\title{
Mechanism of HMGB1 release inhibition from RAW264.7 cells by oleanolic acid in Prunus mume Sieb. et Zucc.
}

\author{
KO-ICHI KAWAHARA ${ }^{1}$, TERUTO HASHIGUCHI ${ }^{1}$, KAZUO MASUDA ${ }^{2}$, ABBI R. SANIABADI $^{3}$, \\ KIYOSHI KIKUCHI ${ }^{1}$, SALUNYA TANCHAROEN ${ }^{4}$, TAKASHI ITO $^{1}$, NAOKI MIURA $^{5}$, \\ YOKO MORIMOTO ${ }^{6}$, KAMAL K. BISWAS ${ }^{1}$, YUKO NAWA ${ }^{1}$, XIAOJIE MENG ${ }^{1}$, YOKO OYAMA ${ }^{1}$, \\ KAZUNORI TAKENOUCHI ${ }^{1}$, BINITA SHRESTHA ${ }^{1}$, HISAYO SAMESHIMA ${ }^{1}$, TOSHIAKI SHIMIZU ${ }^{1}$, \\ TARO ADACHI $^{7}$, MASAKAZU ADACHI $^{7}$ and IKURO MARUYAMA ${ }^{1}$
}

\begin{abstract}
${ }^{1}$ Department of Laboratory and Vascular Medicine Cardiovascular and Respiratory Disorders Advanced Therapeutics, Kagoshima University Graduate School of Medical and Dental Sciences, 8-35-1 Sakuragaoka, Kagoshima 890-8520;

${ }^{2}$ Showa Pharmaceutical, Tokyo; ${ }^{3}$ JIMRO Laboratories, 351-1 Nishiyokote Machi, Takasaki 370-0021, Japan; ${ }^{4}$ Department of Pharmacology, Faculty of Dentistry, Mahidol University, Bangkok 10400, Thailand; ${ }^{5}$ Veterinary Teaching Hospital and Laboratory of Veterinary Diagnostic Imaging, Faculty of Agriculture, Kagoshima University, Kagoshima 890-0065; ${ }^{6}$ Department of Periodontology, Kagoshima University Graduate School of Medical and Dental Sciences, 8-35-1 Sakuragaoka, Kagoshima 890-8544; ${ }^{7}$ AdaBio Co., Ltd., Takasaki City, Japan
\end{abstract}

Received October 2, 2008; Accepted November 24, 2008

DOI: 10.3892/ijmm_00000172

\begin{abstract}
High mobility group box-1 protein (HMGB1), primarily from the nucleus, is released into the extracellular milieu either passively from necrotic cells or actively through secretion by monocytes/macrophages. Extracellular HMGB1 acts as a potent inflammatory agent by promoting the release of cytokines such as tumor necrosis factor (TNF)- $\alpha$, has procoagulant activity, and is involved in death due to sepsis. Accordingly, HMGB1 is an appropriate therapeutic target. In this study, we found that an extract of Prunus mume Sieb. et Zucc. (Ume) fruit (Ume extract), an abundant source of triterpenoids, strongly inhibited HMGB1 release from lipopolysaccharide (LPS)-stimulated macrophage-like RAW264.7 cells. The inhibitory effect on HMGB1 release was enhanced by authentic oleanolic acid (OA), a naturally occurring triterpenoid. Similarly, the HMGB1 release inhibitor in Ume extract was found to be OA. Regarding the mechanisms of the inhibition of HMGB1 release, the OA or Ume extract was found to activate the transcription factor $\mathrm{Nrf} 2$, which binds to the antioxidative responsive element, and subsequently the
\end{abstract}

Correspondence to: Professor Ikuro Maruyama, Department of Laboratory and Vascular Medicine Cardiovascular and Respiratory Disorders Advanced Therapeutics, Kagoshima University Graduate School of Medical and Dental Sciences, 8-35-1 Sakuragaoka, Kagoshima 890-8520, Japan

E-mail: rinken@m3.kufm.kagoshima-u.ac.jp

Key words: high mobility group box 1, Ume extract, oleanolic acid, $\mathrm{Nrf}$, heme oxygenase 1 heme oxygenase (HO)-1 protein was induced, indicating that the inhibition of HMGB 1 release from LPS-stimulated RAW264.7 cells was mediated via the Nrf2/HO-1 system; an essentially antioxidant effect. These results suggested that natural sources of triterpenoids warrant further evaluation as 'rescue' therapeutics for sepsis and other potentially fatal systemic inflammatory disorders.

\section{Introduction}

The high mobility group box 1 protein (HMGB1), a nuclear protein, has two distinct functions in cellular systems. In the nucleus, HMGB1 acts as an intracellular regulator of the transcription process with a crucial role in the maintenance of DNA functions (1). In the extracellular space, HMGB1 is released by all eukaryotic cells upon necrosis or by macrophages in response to inflammatory stimuli (2-4) such as endotoxins, tumor necrosis factor (TNF)- $\alpha$, and C-reactive protein. Extracellular HMGB1 can act as a potent inducer of proinflammatory cytokines including TNF- $\alpha$, interleukin (IL)-6, and IL-1ß from macrophages, thus playing a major role in various inflammatory diseases such as sepsis, rheumatoid arthritis, disseminated intravascular coagulation, periodontitis, xenotransplantation and atherosclerosis (2-10). Therefore, agents capable of inhibiting HMGB1 can be considered to possess therapeutic potential.

Hitherto, studies have shown two approaches toward the inhibition of HMGB1; one comprises a blockade of its activity and the other involves the inhibition of HMGB1 release (2). In mouse models of endotoxemia or septic shock, treatment with a neutralizing anti-HMGB1 antibody increased survival even when treatment was started $24 \mathrm{~h}$ after the onset of endotoxemia or infection (2). Similarly, a blockade of HMGB1 activity by administering thrombomodulin, an anti- 
coagulant protein, to rodents along with thrombin ameliorated the clinical and histological features of the disease $(6,7,11)$, and the inhibition of HMGB1 release was found to be protective against experimental sepsis (2). Several other substances, including the $\mathrm{N}$-terminal kinase activation (JNK) inhibitors and heat shock protein (HSP) 72, are known to inhibit HMGB1 release from lipopolysaccharide (LPS)-stimulated macrophages (13-22). Additionally, natural substances, such as green tea and deep ocean water (DOW), have been shown to inhibit HMGB1 release in RAW264.7 cells $(23,24)$. Therefore, in view of the apparent pathological roles of HMGB1, natural substances capable of blocking HMGB1 release from activated cells might prove to be valuable therapeutic agents.

Prunus mume Sieb. et Zucc. is a variety of Japanese apricot and is known as Ume in Japan (25). The health benefits of Ume are now being widely recognized and strengthened by recent studies that have shown Ume extracts to have strong anticancer and antiproliferative effects in in vivo and in vitro settings (25-28). These studies have also indicated that Ume might possess strong anti-inflammatory effects (25-28). A recent study by Adachi et al (25) isolated 7 triterpenoids from Ume extract. However, the exact mechanism(s) of actions of Ume against pathological processes are yet to be described.

Recently, endogenous heme oxygenase (HO)-1 expression has been shown to protect against the lethal effects of sepsis (29). HO-1 is a cytoprotective enzyme that plays a critical role in defending the body against oxidant-induced injury during inflammation $(29,30)$. In purely inflammatory models of disease, such as endotoxin exposure, HO-1-deficient mice are susceptible to oxidant-induced tissue injury followed by death (30). HO-1 expression has been found to be essential for the activation of the transcription factor Nrf2, which is also a regulator of survival during experimental sepsis (31), suggesting that the Nrf2/HO-1 pathway might be active in the suppression of HMGB1 release. However, to the best of our knowledge, there have been no reports demonstrating a link between the inhibition of HMGB1 release and the Nrf2/HO-1 pathway. In the present study, we showed that the incubation of LPS-stimulated RAW264.7 cells (murine macrophage-like cells) with oleanolic acid (OA), which was extracted from Ume extract, strongly inhibits HMGB1 release and that the mechanism of this inhibition is mediated by the $\mathrm{Nrf} 2 / \mathrm{HO}-1$ pathway.

\section{Materials and methods}

Cell culture. Murine macrophage-like RAW264.7 cells were obtained from the American Type Cell Culture Collection (Manassas, VA) and maintained in RPMI-1640 medium (Sigma, St. Louis, MO) supplemented with $10 \%$ fetal bovine serum (FBS) and $2 \mathrm{mM}$ glutamine.

Fractionation of Ume extract. Isolation of Ume extract was performed as described previously (25-28). Briefly, Ume extract was concentrated and dried with a rotary evaporator. The dried product was dissolved in diethyl ether and fractionated by using a silica gel column elution procedure (methanol:chloroform, 9:1). By this method, we obtained four fractions (F1, F2, F3 and F4).
Stimulation of RAW264.7 cells. RAW264.7 cells ( $2 \times 10^{6}$ cells/ 6-cm dish) were starved for $2 \mathrm{~h}$ in serum-free Opti-MEM-I medium (Invitrogen, Carlsbad, CA) with or without Ume extract (Japan Apricot, Takasaki, Gunma, Japan) and authentic OA (Sigma). Then, $500 \mathrm{ng} / \mathrm{ml}$ of LPS (O111, Alexis, Switzerland) was added to the medium. Authentic OA was used as a positive control against Ume extract.

Preparation of HMGB1 samples for Western blot analysis. Preparations of HMGB 1 samples were performed as previously described (4). Following treatment with LPS, the culture supernatant $(2 \mathrm{ml})$ was incubated with $50 \mu \mathrm{l}$ of heparin-Sepharose 6B (heparin beads) for $4 \mathrm{~h}$ and washed 3 times with $10 \mathrm{mM}$ phosphate buffer ( $\mathrm{pH} 7.0)$. Next, a 50- $\mu 1$ aliquot of buffer [62.5 mM Tris- $\mathrm{HCl}(\mathrm{pH} 6.8), 2 \%$ sodium dodecyl sulphate (SDS), $10 \%$ glycerol and $0.002 \%$ bromophenol blue] was added to the washed heparin beads and boiled for $5 \mathrm{~min}$.

Western blotting. HMGB1 samples (40 $\mu 1)$ were subjected to $12 \%$ SDS-polyacrylamide gel electrophoresis (PAGE), and the separated proteins were transferred to a nitrocellulose membrane (GE Healthcare Bio-Sciences KK, Piscataway, NJ). The membrane was blocked with $5 \%$ non-fat dry milk in Trisbuffered saline (TBS; pH 7.4) containing $0.02 \%$ Tween-20 (TBST) for $1 \mathrm{~h}$ at room temperature (RT) and then incubated with anti-HMGB1 antibody (Shino-Test), Nrf2 antibody (Santa Cruz Biotechnology Inc., Santa Cruz, CA), or HO-1 antibody (Biomol International, L.P., Plymouth Meeting, PA) in TBST containing $1 \%$ non-fat dry milk for $3 \mathrm{~h}$ at RT. After washing, the membrane was incubated with horseradish peroxidase (HRP)-conjugated anti-rabbit IgG polyclonal antibody (Invitrogen) diluted 1:3000 in TBST containing 2.5\% non-fat dry milk for $1 \mathrm{~h}$ at RT. The membrane was washed again, and the immunoreactive bands were visualized by using the ECL detection system (GE Healthcare Bio-Sciences KK).

Immunofluorescence microscopy. Immunofluorescence microscopy was performed as previously described (4). Briefly, 5x105 RAW264.7 cells per well were cultured in 4-well BioCoat Collagen I culture slides (Becton Dickinson Labware). After stimulation, slides were washed with phosphate-buffered saline (PBS) and fixed with $250 \mu 1$ of OptiLyse C (Becton Dickinson) containing 0.1\% Triton X-100 (Sigma). The slides were blocked with $1 \%$ bovine serum albumin (BSA) in PBS containing 0.1\% Triton X-100 (PBST) for $1 \mathrm{~h}$, incubated with $1 \mu \mathrm{g} / \mathrm{ml}$ of rabbit anti-HMGB 1 antibody for $1 \mathrm{~h}$ at RT, and washed with PBST. The slides were incubated with fluorescein isothiocyanate (FITC)-labeled goat anti-rabbit IgG (Invitrogen) for $1 \mathrm{~h}$, and were then washed with PBST. After washing, the slides were examined under an Axioskop microscope (Carl Zeiss, Oberkochen, Germany).

Statistical analysis. The intensity of the protein bands on the Western blots was quantified by using the National Institutes of Health (NIH, Bethesda, MD) Image 1.63 software. The statistical significance of differences in band intensities was determined by applying the Student's t-test, and $\mathrm{P}<0.05$ was considered significant. 
A

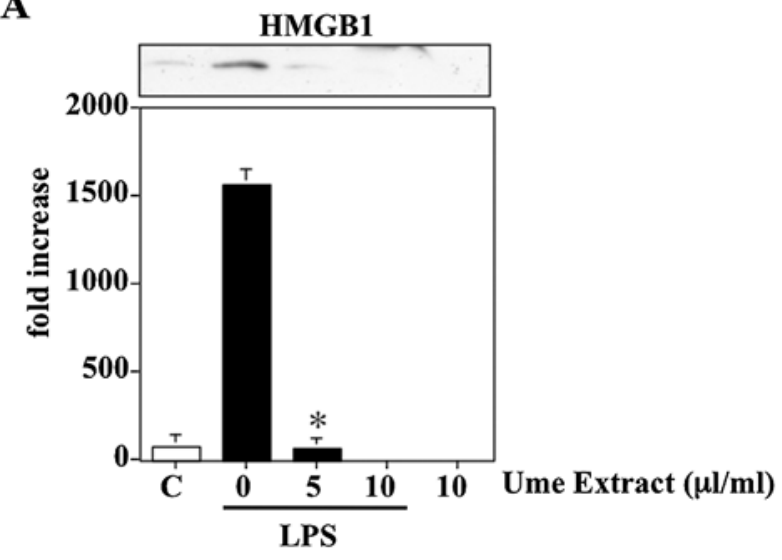

B

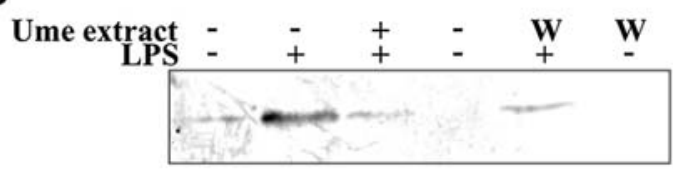

C

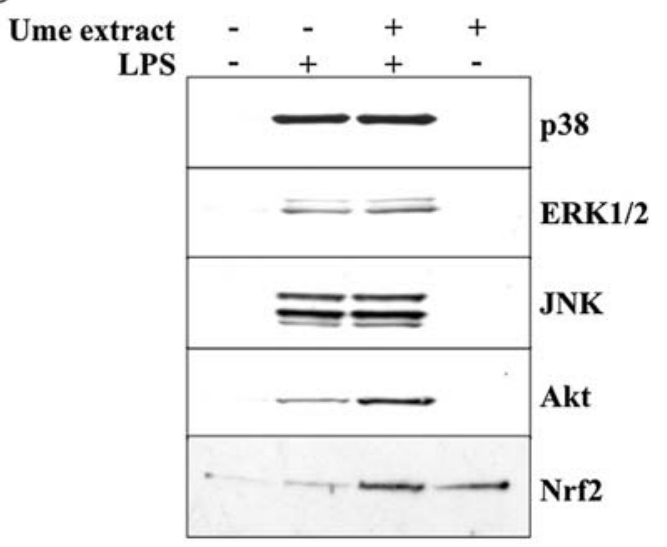

Figure 1. Inhibition of HMGB1 release by Ume extract. (A) Dose-dependent effect of Ume extract in LPS-treated RAW264.7 cells. RAW264.7 cells were incubated with Ume extract $(0,5$, or $10 \mu / \mathrm{ml})$ for $16 \mathrm{~h}$. HMGB1 was measured by Western blotting. ${ }^{*} \mathrm{P}<0.05$. (B) Transient exposure of RAW264.7 cells to Ume extract inhibited LPS-induced HMGB1 release. RAW264.7 cells were incubated with Ume extract for $2 \mathrm{~h}$, and the cells were washed extensively (lane 5) and exposed for $16 \mathrm{~h}$ to LPS (500 ng/ml). HMGB1 was detected by Western blotting. (C) Nrf2 activation by Ume extract in RAW264.7 cells. RAW264.7 cells were pretreated with Ume extract for $2 \mathrm{~h}$ and incubated with LPS for $1 \mathrm{~h}$. Inhibition of ERK1/2, p38MAPK and JNK activation, or activation of Nrf2 by Ume extract was detected by Western blotting.

\section{Results}

Inhibition of LPS-induced HMGB1 release by Ume extract. In this study, we focused on determining whether an Ume extract would inhibit HMGB1 release in LPS-stimulated macrophage-like RAW264.7 cells. RAW264.7 cells were incubated with or without Ume extract (0-10 $\mu \mathrm{l} / \mathrm{ml})$ for $2 \mathrm{~h}$. LPS (500 ng/ $\mathrm{ml}$ ) was then added to the cells and incubated for a further $16 \mathrm{~h}$. The medium was analyzed with Western blotting by using an anti-HMGB1 antibody. As shown in Fig. 1A, Ume extract inhibited HMGB1 release from the stimulated

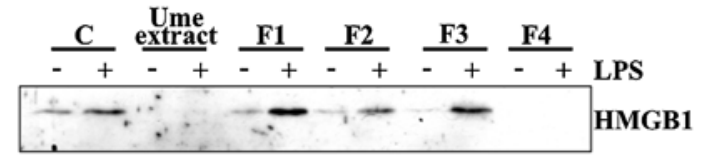

Figure 2. Identification of the Ume fraction with the HMGB1 release inhibitory effect in LPS-stimulated RAW264.7 cells. RAW264.7 cells were incubated with Ume extract and 4 fractions (F1, F2, F3, and F4) as described in Materials and methods for $2 \mathrm{~h}$, and a $500-\mathrm{ng} / \mathrm{ml}$ aliquot of LPS was added to the cells. After incubation for $16 \mathrm{~h}$, the released HMGB1 was detected by Western blotting.

RAW264.7 cells in a dose-dependent manner, clearly indicating that Ume extract contains an inhibitor against HMGB1 release. No cell death by Ume extract was observed under conditions examined in this study (unpublished data).

Transient exposure to Ume extract inhibited LPS-induced $H M G B 1$ release. We sought to determine whether or not transient exposure of cells to Ume extract leads to a sustained inhibition of LPS-induced HMGB1 release. RAW264.7 cells were pretreated with Ume extract $(10 \mu \mathrm{l} / \mathrm{ml})$ for $2 \mathrm{~h}$ (Fig. 1B), and the cells were washed extensively before being exposed for $16 \mathrm{~h}$ to LPS. HMGB1 was then measured in the medium. As was the case with sustained exposure to Ume extract (Fig. 1B, lane 3), even transient incubation with Ume extract strongly inhibited LPS-induced HMGB1 release (Fig. 1B, lane 5).

Induction of Nrf-2 activation by Ume extract. It is known that HMGB1 release is mediated by the mitogen-activated protein kinase (MAPK) pathways, particularly p38MAPK and JNK $(4,16)$. We examined whether the Ume extract suppressed MAPK activation by LPS by Western blot analysis. As shown in Fig. 1C, Ume extract failed to suppress the activation of MAPKs, including ERK1/2, JNK and p38MAPK in the LPS stimulation system. Recently, endotoxin shock was reported to be enhanced in Nrf2 knockout mice; Nrf2 is known to be an antioxidant protein inducer (31). We hypothesized that Ume extract might induce Nrf2 activation. Our investigation revealed that Ume extract indeed activated Nrf2, strongly suggesting that Ume extract might be a rich source of antiinflammatory protein inducers by de novo synthesis. In our conditions, although the molecular weight of Nrf2 is $72 \mathrm{kDa}$, $\mathrm{Nrf} 2$ in the nucleus is $\sim 100 \mathrm{kDa}$. As reported previously, Nrf2 may migrate slowly (41).

The $H M G B 1$ release inhibitory fraction of Ume extract contained $O A$. We wished to identify the inhibitory fraction of the Ume extract against HMGB1 release among the 4 fractions described in Materials and methods. RAW264.7 cells were incubated with $10 \mu \mathrm{g} / \mathrm{ml}$ of F1, F2, F3 or F4, and then $500 \mathrm{ng} /$ $\mathrm{ml}$ of LPS was added. As shown in Fig. 2, both unfractionated Ume extract and F4 showed inhibitory activity against HMGB1 release; F1, F2 and F3 showed no inhibitory action. Additionally, we found that only F4 contained the triterpenoid of OA (unpublished data). Therefore, this investigation strongly suggested that OA might be the inhibitor of HMGB1 release in LPS-treated RAW264.7 cells. 
A

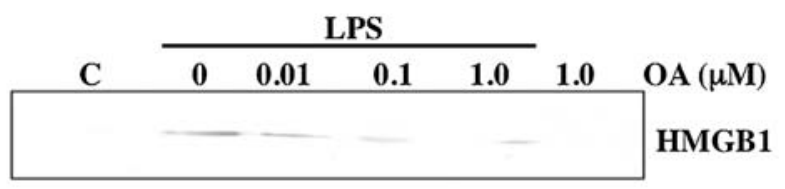

B

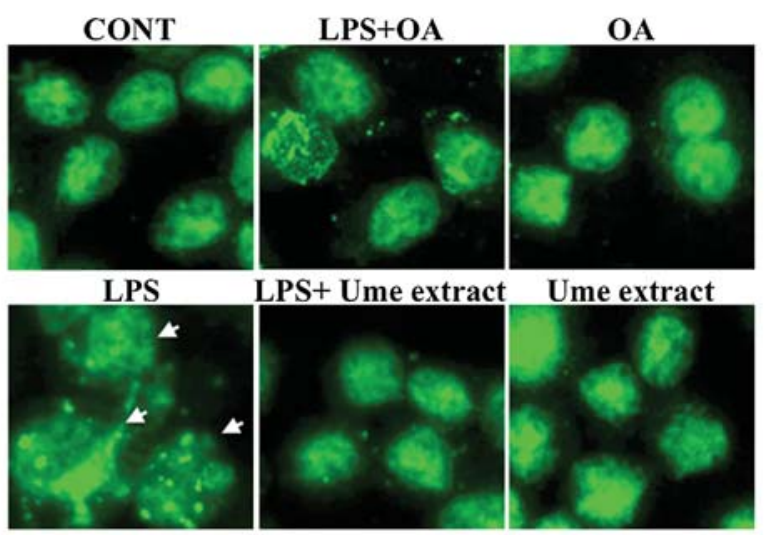

Figure 3. Activation of the Nrf2/HO-1 pathway in OA-treated RAW264.7 cells. (A) Dose-dependent effect of OA on HMGB1 release from LPS-treated RAW264.7 cells. After RAW264.7 cells were incubated with OA $(0,0.01,0.1$ or $1.0 \mu \mathrm{M})$, the cells were incubated with LPS for $16 \mathrm{~h}$. The released HMGB1 was detected by Western blotting. (B) Translocation of HMGB1 from the nuclear to extracellular space in response to Ume extract and OA. RAW264.7 cells were incubated with or without Ume extract $(5 \mu 1 / \mathrm{ml})$ and OA $(1.0 \mu \mathrm{M})$ for $16 \mathrm{~h}$. The fixed cells were incubated with rabbit anti-HMGB1 polyclonal antibody, followed by incubation with FITC-labeled anti-rabbit IgG as a secondary antibody. Original magnification, $x 400$. Arrows indicate translocation of HMGB1 from the nuclear to the extracellular space.

$O A$ in Ume extract inhibited LPS-induced HMGB1 release. Since triterpenoids are abundant in Ume extract (25) and have anti-inflammatory properties (32), we hypothesized that $\mathrm{OA}$, one of the triterpenoids from the Ume extract, might inhibit HMGB1 release. Thus, we examined whether authentic OA inhibits HMGB1 release in LPS-stimulated RAW264.7 cells. As shown in Fig. 3A, OA $(0-1.0 \mu \mathrm{M})$ inhibited HMGB1 release by LPS-stimulated RAW264.7 cells in a dosedependent manner similar to F4 of Ume extract.

Inhibition of HMGB1 translocation in LPS-treated RAW264.7 cells by Ume extract. Additionally, we examined whether the cell nucleus was the source of HMGB1 in stimulated RAW264.7 cells. As shown in Fig. 3B, the released HMGB1 was from the nuclei of the LPS-stimulated RAW264.7 cells (Fig. 3B, LPS), and its release was inhibited by both Ume extract (LPS+Ume extract) and by OA (LPS+OA).

Activation of the Nrf2/HO-1 pathway by OA in Ume extract. To further confirm the above results, we hypothesized that OA induces the HO-1 protein in RAW264.7 cells. This hypothesis was verified by tests that showed OA, in fact, induced the expression of the HO-1 protein in RAW264.7 cells. As shown in Fig. 4, OA (0-1.0 $\mu \mathrm{M})$ was added to RAW264.7 cells and incubated for $5 \mathrm{~h}$; subsequently, both the cytoplasm and the nuclear proteins of the cells were extracted as described in Materials and methods. As shown in Fig. 4, OA

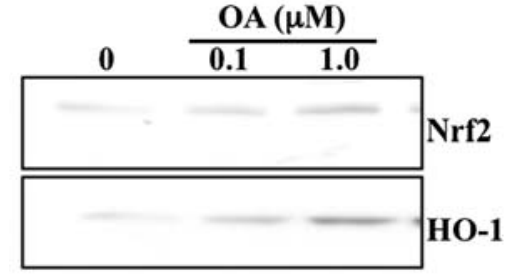

Figure 4. Nrf2 and HO-1 induction by OA in RAW264.7 cells. RAW264.7 cells were incubated with OA $(0,0.1$ or $1.0 \mu \mathrm{M})$ for $3 \mathrm{~h}$, and Nrf2 protein from the nuclear fraction of the cells was analyzed by Western blotting (upper panel). Additionally, RAW264.7 cells were incubated with OA (0 0.1 or $1.0 \mu \mathrm{M}$ ) for $5 \mathrm{~h}$, and $\mathrm{HO}-1$ protein (lower lane) of the cytoplasmic protein fraction of the cells was detected by Western blotting.

induced HO-1 in the cytoplasm of RAW264.7 cells in a dosedependent manner. Similarly, the activation of Nrf2 in the nuclear proteins of RAW264.7 cells by OA was also detected in a dose-dependent manner.

\section{Discussion}

A recent study (25) found Ume extract to be a very rich natural source of triterpenoids, which have strong health-enhancing and disease-suppressing effects $(25,32)$. In the present study, we used LPS-stimulated RAW264.7 cells as a model for HMGB1 release and found that Ume extract has a potent inhibitory effect on HMGB1 release. The effects of the Ume extract were dose-dependent and were mimicked by OA, a naturally occurring triterpenoid that we extracted from the Ume extract. The actions of Ume extract-derived OA were confirmed by using authentic OA. Furthermore, we demonstrated that the inhibitory action of the Ume extract occurred via the activation of Nrf2 and induction of HO-1 protein (the Nrf2/ HO-1 pathway) in RAW264.7 cells, thus essentially being an antioxidant effect.

Hitherto, studies have shown that JNK inhibition and an increase in the expression of HSP72 suppress HMGB1 release by LPS-stimulated RAW264.7 cells $(16,17)$. Contrary to these reports, both Ume extract and authentic OA failed to affect JNK activation, induction of HSP72 protein, or anticoagulant activity (data not presented). However, JNK inhibition, HSP72, and substances with strong antioxidant actions, such as green tea and DOW, inhibit HMGB1 release and also protect against death in animal models of sepsis involving oxidative stress (33-39). These observations support our notion that Ume extract contains substances with strong antioxidant effects (described below).

Ume extract is known to be highly effective in the prevention and treatment of cancer in many animal models and for apoptosis induction in tumour cells. Despite these reports, Ume substances have not yet been used to treat disease in clinical settings (25-28); possibly, such use is dependent on the outcome of future clinical trials in humans. In this study, the Ume extract fraction (F4), abundant in triterpenoid/OA, inhibited HMGB1 release, suggesting that an antioxidant effect of triterpenoid is involved in the inhibition of HMGB1 release. Since many triterpenoids are widely used in Asian medicine and are known to occur in natural products, akin to OA/ triterpenoids in Ume extract which has multiple health 
benefits including antioxidant, anti-inflammatory and anticancer effects (32), clinical trials to fully understand the therapeutic potentials of Ume extracts are warranted. Furthermore, in this study, we demonstrated the antioxidant activity to be associated with the activation of the transcription factor Nrf2. In response to oxidative stress, Nrf2 is released from KEAP1 and then activates an antioxidant response element on the promoter of phase 2 response genes, which include HO-1, glutathione synthesis and quinone reductase. One consequence of activating the phase 2 response is a reduction in the reactive oxygen species. Thus, Nrf2 is required for such an attenuation of oxidative stress.

In endotoxemia, the upregulation of HO-1 is thought to be beneficial in combating the detrimental consequences of exacerbated inflammation. Administration of HO-1 inhibitors at high doses (decreasing $\mathrm{HO}$ enzyme activity below basal levels) made rats more susceptible to LPS-induced death (40). Similarly, mouse cells lacking HO-1 were susceptible to LPSinduced oxidative injury. Hence, the induction of endogenous HO- 1 counteracts increased inflammation and oxidative injury associated with endotoxemia via antioxidant action.

In conclusion, the present study provides evidence that Prunus mume Sieb. et Zucc extract and oleanolic acid inhibit HMGB1 release from stimulated RAW264.7 cells via the Nrf2/HO-1 pathway and thereby play major roles in the regulation of cell survival in endotoxemia and other inflammatory conditions. Clinical trials are required to fully understand the therapeutic potential of Ume extracts.

\section{Acknowledgements}

We thank Nobue Uto, Tomomi Morizono and Tomoka Nagasato for their excellent technical support. This study was supported by a research grant from the Ministry of Education, Culture, Sports, Science and Technology of Japan by grant-in-aid no. 19791618 (Y.M.), by grant-in-aid no. 17100007 (S.T.), and by a Health and Labour Sciences Research Grant from the Ministry of Health, Labour and Welfare (I.M.).

\section{References}

1. Lu J, Kobayashi R and Brill SJ: Characterization of a high mobility group 1/2 homolog in yeast. J Biol Chem 271: 33678-33685, 1996.

2. Wang H, Bloom O, Zhang M, et al: HMG-1 as a late mediator of endotoxin lethality in mice. Science 285: 248-251, 1999.

3. Taniguchi N, Kawahara K, Yone K, et al: High mobility group box chromosomal protein 1 plays a role in the pathogenesis of rheumatoid arthritis as a novel cytokine. Arthritis Rheum 48: 971-981, 2003.

4. Kawahara K, Kamal KB, Unoshima M, et al: CRP induces high mobility group box-1 protein release through a $\mathrm{p} 38 \mathrm{MAPK}$ in the macrophage cell line RAW264.7 cells. Cardiovasc Pathol 17: 129-138, 2008

5. Park JS, Svetkauskaite D, He Q, et al: Involvement of toll-like receptors 2 and 4 in cellular activation by high mobility group box 1 protein. J Biol Chem 279: 7370-7377, 2004.

6. Ito T, Kawahara K, Nakamura T, et al: High-mobility group box 1 protein promotes development of microvascular thrombosis in rats. J Thromb Haemost 5: 109-116, 2007.

7. Ito T, Kawahara KI, Okamoto K, et al: Proteolytic cleavage of high mobility group box 1 protein by thrombin-thrombomodulin complexes. Arterioscler Thromb Vasc Biol 28: 1825-1830, 2008

8. Morimoto Y, Kawahara K, Tancharoen S, et al: Tumor necrosis factor-alpha stimulates gingival epithelial cells to release high mobility-group box 1. J Periodontal Res 43: 76-83, 2008.
9. Kawahara K, Setoyama K, Kikuchi K, et al: HMGB1 release in co-cultures of porcine endothelial and human $\mathrm{T}$ cells. Xenotransplantation 14: 636-641, 2007.

10. Porto A, Palumbo R, Pieroni M, et al: Smooth muscle cells in human atherosclerotic plaques secrete and proliferate in response to high mobility group box 1 protein. FASEB J 20: 2565-2566, 2006.

11. Inoue $\mathrm{K}$, Kawahara $\mathrm{K}$, Biswas $\mathrm{KK}$, et al: HMGB1 expression by activated vascular smooth muscle cells in advanced human atherosclerosis plaques. Cardiovasc Pathol 16: 136-143, 2007.

12. Kokkola R, Li J, Sundberg E, et al: Successful treatment of collagen-induced arthritis in mice and rats by targeting extracellular high mobility group box chromosomal protein 1 activity. Arthritis Rheum 48: 2052-2058, 2003.

13. Ulloa L, Ochani M, Yang H, et al: Ethyl pyruvate prevents lethality in mice with established lethal sepsis and systemic inflammation. Proc Natl Acad Sci USA 99: 12351-12356, 2002.

14. Wang $\mathrm{H}$, Liao $\mathrm{H}$, Ochani $\mathrm{M}$, et al: Cholinergic agonists inhibit HMGB1 release and improve survival in experimental sepsis. Nat Med 11: 1216-1221, 2004.

15. Killeen ME, Englert JA, Stolz DB, et al: The phase 2 enzyme inducers ethacrynic acid, DL-sulforaphane, and oltipraz inhibit lipopolysaccharide-induced high-mobility group box 1 secretion by RAW 264.7 cells. J Pharmacol Exp Ther 316: 1070-1079, 2006.

16. Jiang W, Bell CW and Pisetsky DS: The relationship between apoptosis and high-mobility group protein 1 release from murine macrophages stimulated with lipopolysaccharide or polyinosinic-polycytidylic acid. J Immunol 178: 6495-6503, 2007.

17. Tang D, Kang R, Xiao W, et al: Nuclear heat shock protein 72 as a negative regulator of oxidative stress (hydrogen peroxide)induced HMGB 1 cytoplasmic translocation and release. J Immunol 178: 7376-7384, 2007.

18. Chorny A and Delgado M: Neuropeptides rescue mice from lethal sepsis by down-regulating secretion of the late-acting inflammatory mediator high mobility group box 1 . Am $\mathrm{J}$ Pathol 172: 1297-1307, 2008

19. Chorny A, Anderson P, Gonzalez-Rey E and Delgado M: Ghrelin protects against experimental sepsis by inhibiting highmobility group box 1 release and by killing bacteria. J Immunol 180: 8369-8377, 2008

20. Hagiwara S, Iwasaka H, Matsumoto S and Noguchi T: High dose antithrombin III inhibits HMGB1 and improves endotoxininduced acute lung injury in rats. Intensive Care Med 34: 361-367, 2008.

21. Hagiwara S, Iwasaka H, Hidaka S, Hishiyama S and Noguchi T: Danaparoid sodium inhibits systemic inflammation and prevents endotoxin-induced acute lung injury in rats. Crit Care 12: R43, 2008.

22. Hagiwara S, Iwasaka H, Hasegawa A, Koga H and Noguchi T: Effects of hyperglycemia and insulin therapy on high mobility group box 1 in endotoxin-induced acute lung injury in a rat model. Crit Care Med 36: 2407-2413, 2008.

23. Li W, Ashok M, Li J, Yang H, Sama AE and Wang H: A major ingredient of green tea rescues mice from lethal sepsis partly by inhibiting HMGB1. PLoS ONE 11: e1153, 2007.

24. Kawahara K, Tancharoen S, Hashiguchi T, et al: Inhibition of HMGB 1 by deep ocean water attenuates endotoxin-induced sepsis. Med Hypotheses 68: 1429-1430, 2007.

25. Adachi M, Suzuki Y, Mizuta T, et al: The Japanese apricot Prunus mume Sieb. et Zucc (ume) is a rich natural source of novel anti-cancer substance. Int J Food Prop 10: 375-384, 2007.

26. Nakagawa A, Sawada T, Okada T, Ohsawa T, Adachi M and Kubota K: New antineoplastic agent, MK615, from UME (a variety of) Japanese apricot inhibits growth of breast cancer cells in vitro. Breast J 13: 44-49, 2007.

27. Mori S, Sawada T, Okada T, Ohsawa T, Adachi M and Keiichi K: New anti-proliferative agent, MK615, from Japanese apricot 'Prunus mume' induces striking autophagy in colon cancer cells in vitro. World J Gastroenterol 13: 6512-6517, 2007.

28. Okada T, Sawada T, Osawa T, Adachi M and Kubota K: MK615 inhibits pancreatic cancer cell growth by dual inhibition of Aurora A and B kinases. World J Gastroenterol 14: 1378-1382, 2008.

29. Chung SW, Liu X, Macias AA, Baron RM and Perrella MA: Heme oxygenase-1-derived carbon monoxide enhances the host defense response to microbial sepsis in mice. J Clin Invest 118: 239-247, 2008 . 
30. Wiesel P, Patel AP, DiFonzo N, et al: Endotoxin-induced mortality is related to increased oxidative stress and end-organ dysfunction, not refractory hypotension, in heme oxygenase-1deficient mice. Circulation 102: 3015-3022, 2000.

31. Thimmulappa RK, Lee H, Rangasamy T, et al: Nrf2 is a critical regulator of the innate immune response and survival during experimental sepsis. J Clin Invest 116: 984-995, 2006.

32. Liby KT, Yore MM and Sporn MB: Triterpenoids and rexinoids as multifunctional agents for the prevention and treatment of cancer. Nat Rev Cancer 5: 357-369, 2007.

33. Biswas KK, Sarker KP, Abeyama K, et al: Membrane cholesterol but not putative receptors mediates anandamide-induced hepatocyte apoptosis. Hepatology 38: 1167-1177, 2003.

34. Cízková D, Rosocha J, Vanick I, Radonák J, Gálik J and Cízek M: Induction of mesenchymal stem cells leads to HSP72 synthesis and higher resistance to oxidative stress. Neurochem Res 31: 1011-1020, 2006.

35. Monge $\mathrm{M}$, Ledemé $\mathrm{N}$ and Mazouz $\mathrm{H}$ : Insulin maintains plasma antioxidant capacity at an early phase of kidney transplantation. Nephrol Dial Transplant 22: 1979-1985, 2007.

36. Tunçel N, Erden S, Uzuner K, Altiokka G and Tunçel M: Ischemic-reperfused rat skeletal muscle: the effect of vasoactive intestinal peptide (VIP) on contractile force, oxygenation and antioxidant enzyme systems. Peptides 18: 269-275, 1997.
37. El Eter E, Al Tuwaijiri A, Hagar H and Arafa M: In vivo and in vitro antioxidant activity of ghrelin: attenuation of gastric ischemic injury in the rat. J Gastroenterol Hepatol 22: 1791-1799, 2007.

38. Lim SC, Choi JE, Kim CH, et al: Ethyl pyruvate induces necrosis-to-apoptosis switch and inhibits high mobility group box protein 1 release in A549 lung adenocarcinoma cells. Int J Mol Med 20: 187-192, 2007.

39. Barichello T, Machado RA, Constantino L, et al: Antioxidant treatment prevented late memory impairment in an animal model of sepsis. Crit Care Med 35: 2186-2190, 2007.

40. Otterbein L, Sylvester SL and Choi AMK: Hemoglobin provides protection against lethal endotoxemia in rats: the role of heme oxygenase-1. Am J Respir Cell Mol Biol 13: 595-601, 1995.

41. Kwak MH, Itoh K, Yamamoto M, et al: Role of transcription factor Nrf2 in the induction of hepatic phase 2 and antioxidative enzymes in vivo by the cancer chemoprotective agent, $3 \mathrm{H}-1,2$ dimethiole-3-thione. Mol Med 7: 135-145, 2001. 